\title{
Evadir ou persistir? Uma disciplina introdutória centrada no fomento à persistência nos cursos de licenciatura em Física!
}

Leonardo Albuquerque Heidemann*, Sandro Luiz Giongo**, Kaluti Rossi de Martini Moraes***

\section{Resumo}

As altas taxas de evasão nos cursos de licenciatura em Física constituem em um importante problema para a educação brasileira. Formaturas com menos de dez alunos são frequentes nesses cursos ao mesmo tempo em que a Educação Básica carece de profissionais formados na área. Ações efetivas de combate à evasão são fundamentais, portanto, para as universidades do país. Neste artigo, relatamos as ações que estão sendo desenvolvidas em uma disciplina introdutória das licenciaturas em Física da Universidade Federal do Rio Grande do Sul (UFRGS) com o objetivo de fomentar a motivação dos estudantes para persistirem nos cursos. Fundamentados no Modelo da Motivação da Persistência do Estudante de Vincent Tinto, desenvolvemos atividades com o objetivo de promover a melhora das percepções dos estudantes sobre: $i$. suas capacidades para suprirem as demandas do curso (crenças de autoeficácia); ii. seus pertencimentos como membros de uma comunidade que valoriza suas participações na instituição (senso de pertencimento); e iii. o valor e/ou relevância dos estudos previstos no currículo dos seus cursos (percepção de currículo). A avaliação da disciplina evidencia que ela tem motivado os estudantes para persistirem, fomentando entre eles a construção de uma identidade docente, uma maior compreensão conceitual de teorias da Física, e o estabelecimento de relações entre os conteúdos previstos no currículo.

Palavras-chave: Métodos ativos de ensino, Evasão, Licenciatura em Física.

- Departamento de Física, Instituto de Física da Universidade Federal do Rio Grande do Sul. Brasil. E-mail: leonardo.h@ufrgs.br

** Mestrando no Programa de Pós-Graduação em Ensino de Física da Universidade Federal do Rio Grande do Sul. Brasil. E-mail: sandro.giongo@ufrgs.br

..* Doutorando no Programa de Pós-Graduação em Ensino de Física da Universidade Federal do Rio Grande do Sul. Brasil. E-mail: kaluti.moraes@gmail.com

Recebido em: 15/10/2019 - Aceito em: 04/01/2020

https://doi.org/ 10.5335/rbecm.v3i1.10091

http://creativecommons.org/licenses/by-nc-nd/4.0 


\section{Introdução}

Aproximadamente 50\% dos professores que atuam no Ensino Médio no Brasil não possuem formação na área em que ensinam. Esse cenário se torna ainda mais grave quando se é analisado especificamente os professores de Física e constatado que apenas 26,7\% deles possui diploma de curso superior na área (SALDAÑA, 2017). No entanto, as formaturas de cursos de licenciatura em Física tradicionalmente contam com poucos concluintes. No caso do Instituto de Física da Universidade Federal do Rio Grande do Sul (IF/UFRGS), por exemplo, contexto em que esse relato está inserido, tradicionalmente são diplomados menos de dez estudantes por semestre, sendo frequentes formaturas com menos de cinco concluintes.

Um dos fatores que explicam esse cenário reside nos altos índices de evasão nos cursos de Física. Ainda que as particularidades envolvidas na decisão de evadir desses cursos possam estar relacionadas com indicadores socioeconômicos dos estudantes, as experiências vivenciadas na Universidade são decisivas quando eles evadem (DAITX et al., 2016; PALHARINI, 2004; BRAGA; PEIXOTO; BOGUTCHI, 2003; TINTO, 1975; LIMA JUNIOR; OSTERMANN; REZENDE, 2012). Analisando especificamente o IF/UFRGS, Lima Junior (2013), em um importante estudo vencedor do Prêmio CAPES de Tese na área de Ensino em 2014, constata que a evasão ou a permanência nos cursos de graduação da instituição estão vinculadas com algumas das disposições institucionais do IF/UFRGS, quais sejam: individualismo (em oposição ao aprendizado colaborativo), autodidatismo (em oposição ao aprendizado com participação qualificada e responsável do professor), performatividade ostensiva (oposta ao aceitar as limitações do outro), valorização da dificuldade e da análise científica formal (em oposição à análise conceitual), valorização da formação para o ensino superior (em oposição à formação para a educação básica). O autor argumenta ainda que há ações ao alcance da instituição que poderiam melhorar sensivelmente a experiência dos alunos na instituição com provável redução das taxas de evasão. Entre elas, destaca a necessidade de se "criar estratégias que visem a distribuição mais equilibrada de recursos entre alunos de licenciatura e bacharelado garantindo, por exemplo, uma oferta de disciplinas menos díspar entre esses dois cursos" (LIMA JUNIOR, 2013, p. 250).

Alinhado com as conclusões construídas no estudo de Lima Junior (2013), o novo currículo dos cursos de licenciatura do IF/UFRGS foram implementados no primei- 
ro semestre de 2018 com o propósito de promover a construção de uma identidade própria para os cursos de licenciatura, valorizando-os e aproximando-os da escola básica. Essa implementação, aliada a uma valorização institucional dos cursos de licenciatura, representava uma excelente oportunidade para o desenvolvimento de ações de combate à evasão. Tal cenário proporcionou o estabelecimento de um grupo de pesquisa-ação coordenado pelo primeiro autor deste artigo. Centrado no problema da evasão nos cursos de licenciatura do IF/UFRGS, esse grupo conta com a participação de professores e estudantes de graduação e de pós-graduação que realizam uma série de ações focadas no fomento à persistência dos licenciandos. O delineamento e a implementação da disciplina intitulada "Introdução à Física", incorporada ao primeiro semestre dos cursos no novo currículo, é uma dessas ações, e o objetivo deste artigo é relatar os desafios envolvidos nesse empreendimento pioneiro no IF/UFRGS.

As atividades desenvolvidas na disciplina "Introdução à Física" foram delineadas com base no Modelo da Motivação da Persistência do Estudante de Vincent Tinto (2017). Trata-se de um modelo organizacional, pois mobiliza aspectos pessoais, sociais e institucionais para explicar a evasão, e também sociológico, pois busca explicações para a evasão no contexto social do estudante e da instituição, desviando o foco único das questões psicológicas. Desse modo, é um modelo interacionista. Assume-se que o indivíduo tem algum nível de comprometimento com a instituição no momento em que realiza o ingresso, assim como tem como meta a conclusão da graduação. Este comprometimento se consolida imerso no conjunto de relações entre os sistemas background familiar, escolarização anterior do indivíduo, assim como suas competências e habilidades. Entretanto, após o ingresso, Tinto defende que existe uma primazia dos conjuntos de relações que o indivíduo estabelece no ambiente universitário para influenciar a decisão do estudante em permanecer ou evadir do curso.

Tinto (2017) argumenta que a motivação do estudante para persistir em um curso de graduação pode ser entendida como o resultado da interação entre seus objetivos, suas crenças de autoeficácia, seu senso de pertencimento e sua percepção de currículo do estudante. As crenças de autoeficácia, no contexto de Tinto, são entendidas as crenças do estudante em suprir as demandas do curso de graduação. O senso de pertencimento é um construto psicológico que pode ser entendido como o sentimento de fazer parte e ter seu envolvimento valorizado nas suas relações. A 
percepção de currículo engloba, na perspectiva do estudante, a percepção do valor e da relevância dos estudos previstos no currículo do seu curso.

A disciplina "Introdução à Física" é essencialmente conduzida por meio de atividades pautadas por metodologias ativas, contextualizadas e problematizadas a partir de debates sobre o papel da educação científica, a natureza da Ciência e o trabalho colaborativo. Tal escolha foi dirigida por resultados da literatura que mostram que essas atividades têm potencial para proporcionar que os estudantes se sintam motivados para persistir a partir da adequação de suas crenças de autoeficácia, seus sensos de pertencimento e suas percepções de currículo. A decisão de implementar metodologias ativas de ensino, por exemplo, é apoiada em resultados da literatura que mostram que elas fomentam a construção de crenças de autoeficácia mais positivas (e.g., GOK, 2012; ESPINOSA, 2016; SAWTELLE et al., 2012; DOWD; ARAUJO; MAZUR, 2013; KAPUCU; BAHÇIVAN, 2015). No que segue, são expostos o referencial teórico que dirigiu a experiência relatada, o contexto de implementação, os objetivos da disciplina, os procedimentos didáticos realizados e, por fim, uma avaliação da implementação.

\section{Referencial Teórico}

Tinto propôs em 1975 um dos modelos mais utilizados em estudos sobre evasão nos cursos superiores: o Modelo de Integração do Estudante (LIMA JUNIOR, 2013; CASTRO, 2012; MASSI; VILLANI, 2015). Trata-se de um modelo organizacional, pois vincula aspectos individuais, sociais e institucionais com a decisão de evadir. Ademais, é dito um modelo interacionista que não privilegia o indivíduo ou a instituição, defendendo que a falta de interação entre alunos e instituições é o elemento fundamental da evasão. Mais precisamente, Tinto expõe dois processos que, conjuntamente, são essenciais nessas relações: a integração acadêmica e a integração social.

A integração acadêmica pode ser entendida como o processo resultante da interação entre as características pessoais do estudante e o que Tinto (1975) denomina de sistema acadêmico. Esse sistema congrega as práticas de ensino dirigidas para a educação formal dos estudantes. Essas práticas usualmente ocorrem nas salas de aula, laboratórios e bibliotecas. O sentimento de desenvolvimento intelectual do estudante, a partir das experiências acadêmicas, desempenha um papel importante 
nesse processo. Desse modo, a integração acadêmica dos estudantes está relacionada com os seus sentimentos de estarem integrados ao sistema acadêmico, suprindo as demandas desse sistema, conseguindo construir os conhecimentos previstos, identificando-se com os conteúdos abordados e com as normas e valores compartilhados. A integração social, por sua vez, constitui-se nas relações do estudante com o que Tinto denomina de sistema social. Esse sistema congrega as interações entre os estudantes em suas vidas cotidianas na universidade, quando estão fora do domínio acadêmico. Essas interações ocorrem em suas moradias, restaurantes, bares etc. $\mathrm{O}$ autor ainda salienta a importância dos contatos informais que o estudante estabelece com os professores e demais funcionários da instituição. A integração social se refere então ao sentimento dos estudantes de fazer parte de um grupo, possibilitando que encontram um ambiente ameno e confortável na universidade (TINTO, 1975).

Em essência, o modelo de Tinto $(1975,1993)$ indica que a decisão de evadir de um estudante é originada a partir de sucessivas falhas no estabelecimento de integrações acadêmicas e sociais. É importante perceber aqui que o autor entende que os acontecimentos precedentes ao ingresso na Universidade são menos importantes na decisão de evadir do que as interações que se constroem nos sistemas acadêmico e social. No entanto, as experiências anteriores se manifestam nesse processo na medida em que elas influenciam na percepção do estudante sobre a importância de ser aluno da Universidade e de concluir a graduação, obtendo o diploma de curso superior, que também são fatores importantes na decisão de evadir. A Figura 1 ilustra o processo de decisão de evasão construído por Tinto $(1975,1993)$. Destacamos que, em última análise, são as vivências no contexto universitário que atualizam essa percepção do estudante, exercendo predominantemente influência na sua decisão de evadir ou persistir através dos processos de integração acadêmica e social. 
Figura 1: Representação esquemática das interações entre os estudantes com o sistema social e acadêmico segundo Tinto

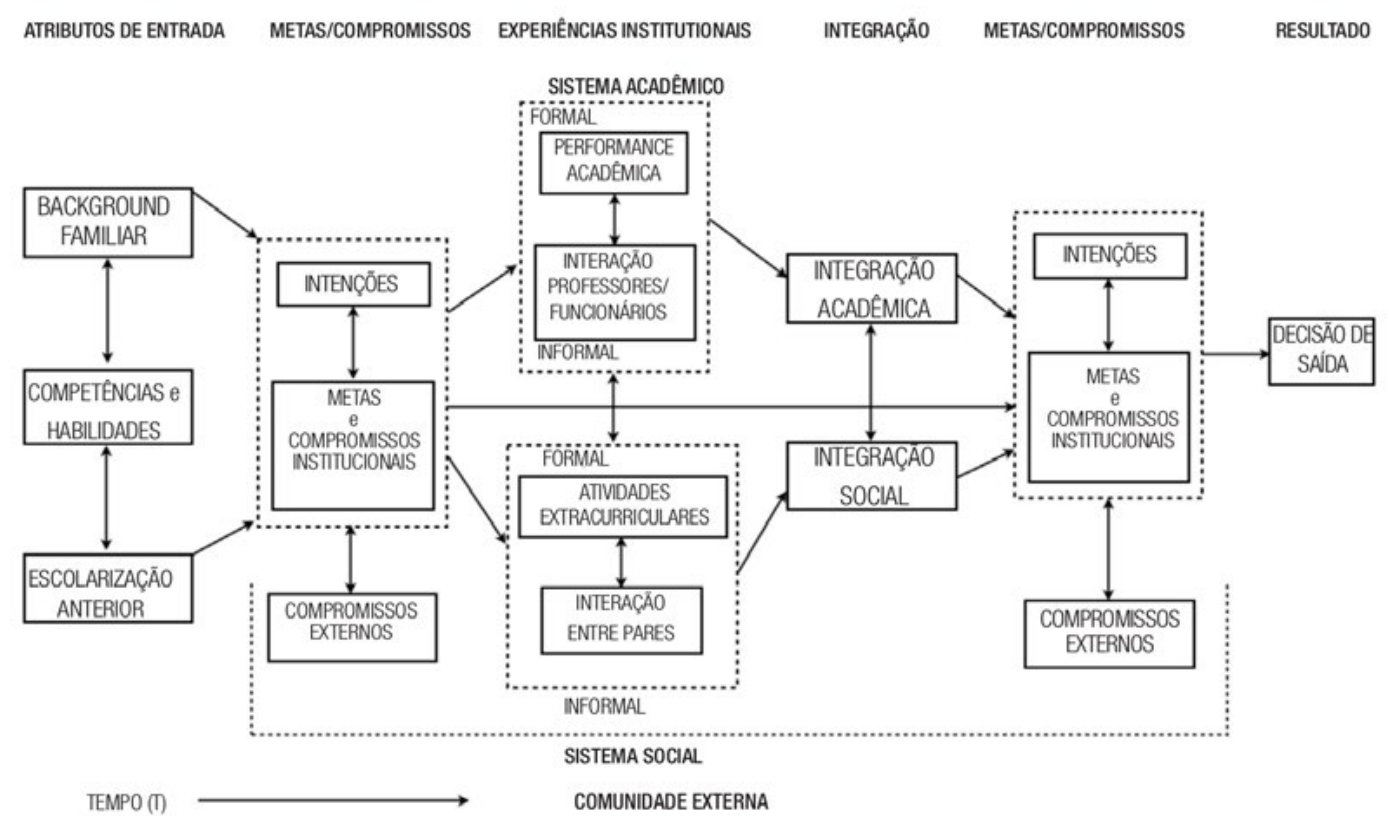

Fonte: extraído de MASSI; VILLANI, 2015.

Do ponto de vista institucional, o combate à evasão está, para Tinto $(1975,1993)$, relacionado com ações que promovam a integração acadêmica e social dos estudantes. Dessa perspectiva, fomentar situações de contato entre os estudantes e possibilitar canais de apoio para a complementação dos estudos sobre os conteúdos abordados no sistema acadêmico podem ser entendidos como exemplos de ações alinhadas ao combate à evasão, ou seja, como ações que promovem a retenção dos estudantes na Universidade. Tinto (2017) argumenta, no entanto, que a compreensão mais ampla do processo de evasão requer uma análise do problema do ponto de vista do estudante. Para isso, é necessário, segundo o autor, desviar o foco da retenção do estudante no curso, que é típica do olhar institucional, para a sua persistência no curso, que pode ser entendida como uma manifestação da sua motivação para continuar na Universidade. Em função disso, Tinto (2017) propõe um modelo vinculando características dinâmicas dos estudantes com a motivação deles para continuar na Universidade.

No modelo de Tinto (2017), metas, motivação, persistência, crenças de autoeficácia, senso de pertencimento, e percepção do currículo são elementos intimamente 
relacionados quando os estudantes constroem suas caminhadas na Universidade. Tais relações são sintetizadas na Figura 2.

Figura 2: Representação esquemática das principais relações que influenciam na persistência dos estudantes para continuar em um curso de graduação segundo Tinto (2017)

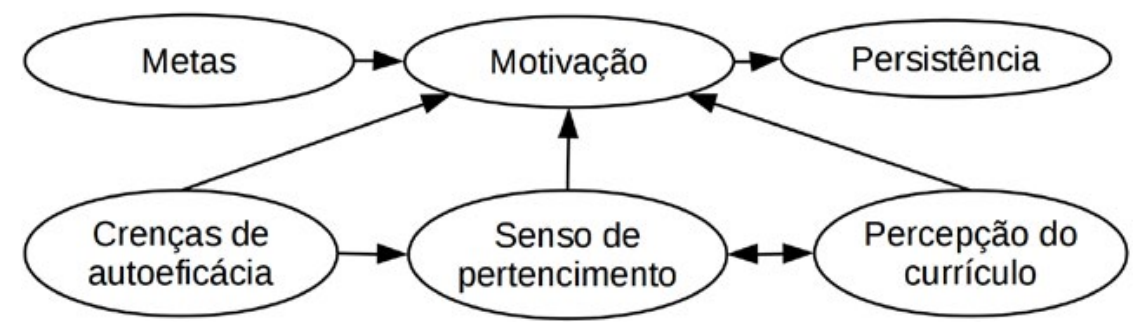

Para Tinto (2017), a persistência de um estudante em um curso de graduação é a manifestação de que ele está motivado para continuar seus estudos. Essa motivação é influenciada pelas metas dos estudantes. Cabe destacar, no entanto, que metas e motivações podem estar vinculadas de diferentes formas para diferentes estudantes. Alguns alunos podem ter a meta de concluir um curso de graduação em função de benefícios intrínsecos às experiências vividas na Universidade como, por exemplo, o aprendizado proporcionado e a construção de autonomias. Outros, podem estar concentrados em benefícios extrínsecos decorrentes da conclusão do curso de graduação como, por exemplo, os salários que se pode alcançar e o status social da ocupação proporcionada com o diploma. Em virtude dessas características das metas dos estudantes, as experiências vividas na Universidade influenciarão de forma distinta nas suas motivações para concluir seus cursos. O modelo de Tinto parte da suposição de que os estudantes iniciam seus estudos com, pelo menos, algum grau de comprometimento para concluir sua graduação na instituição em que ingressaram, e que as experiências vividas na Universidade influenciam nesse comprometimento, influenciando, por sua vez, na motivação deles para concluir o curso.

Um dos principais elementos que interfere na motivação dos estudantes, segundo Tinto (2017), consiste nas suas crenças de autoeficácia. Elas são definidas como as crenças dos indivíduos sobre suas capacidades de obterem sucesso em situações ou tarefas específicas; são manifestações de como os indivíduos se percebem a partir de experiências e interações com outras pessoas (BANDURA, 1997). O autor destaca que as crenças de autoeficácia são aprendidas, e não herdadas. Essas crenças influenciam 
em como uma pessoa trata de metas, tarefas e desafios. Indivíduos com crenças de autoeficácia mais positivas para realizar uma determinada tarefa se engajam nessa tarefa; se esforçam mais e persistem por mais tempo na conclusão dessa tarefa, mesmo quando encontram significativas dificuldades. Portanto, as crenças de autoeficácia são decisivas na persistência do estudante para continuar em seus cursos, e a qualidade delas variam a partir das suas experiências dentro da Universidade.

O segundo elemento que influencia na motivação dos estudantes destacado por Tinto (2017) é o que ele denomina de senso de pertencimento. Tal construto reflete o quanto os estudantes se percebem como membros de uma comunidade (e.g., colegas, veteranos, professores) que valoriza sua participação. Um alto senso de pertencimento resulta em um vínculo com uma comunidade que se manifesta por meio de um compromisso, principalmente quando surgem desafios. Esse pertencimento pode ser relativo a comunidades de diferentes características na Universidade. Pode envolver tanto um compromisso com colegas que compartilham de um interesse como com a instituição de um modo mais geral. Tinto (2017) destaca que, ainda que o senso de pertencimento a pequenas comunidades possa estimular a persistência, pois os estudantes podem construir relações colaborativas para o enfrentamento de dificuldades, o senso de pertencimento à Universidade é mais diretamente relacionado às motivações do aluno para persistir no curso. Esse último é moldado, primordialmente, pelo ambiente institucional e pelas interações cotidianas com professores e funcionários que, por sua vez, acabam por transmitir aos estudantes uma visão da Universidade sobre o papel dos seus estudantes na sua estrutura.

O terceiro importante elemento decisivo para a construção da motivação dos estudantes é a percepção do currículo, ou seja, é a percepção dos estudantes sobre o valor e/ou relevância dos estudos previstos no currículo do seu curso. As variações dessa percepção que ocorrem enquanto o estudante evolui em seu curso de graduação dependem de uma variedade de fatores como, por exemplo, os métodos de ensino empregados nas disciplinas, as percepções sobre a qualidade do planejamento das atividades de ensino e se o seu estilo de aprendizado é considerado pelos professores. Em síntese, para que os estudantes persistam em um curso, eles precisam perceber que o currículo que cursarão tem qualidade suficiente para justificar o tempo e esforço dispendido.

Na disciplina "Introdução à Física", as atividades delineadas são essencialmente focadas na construção de crenças de autoeficácia, senso de pertencimento e percepção de currículo mais positivas entre os estudantes. No que segue, descrevemos o contexto dessa disciplina. 


\section{Contexto da Experiência}

Os cursos de licenciatura em Física da UFRGS vivem imersos em um contexto de grande valorização da pesquisa e da formação de alto nível. A Universidade é uma das mais importantes do Brasil, tendo frequentado posições de destaque em rankings nacionais e internacionais (BRASIL, 2018a; 2018b). O IF/UFRGS, com 60 anos de história, destaca-se por sua produção científica qualificada e internacionalmente reconhecida. Entre os grupos de pesquisa da instituição, destaca-se o Grupo de Pesquisa em Ensino de Física do IF/UFRGS que, a partir da sua fundação, em 1967, tornou-se referência na América Latina entre pesquisadores da área de ensino de Ciências e Matemática. A importância desse grupo possibilitou o estabelecimento do Programa de Pós-Graduação em Ensino de Física (PPGEnFís) no IF/UFRGS em 2002, proporcionando a formação de 142 mestres e 25 doutores até 2019.

O curso de licenciatura em Física diurno do IF/UFRGS foi fundado em 1957, enquanto que o noturno existe desde 1999. Tais cursos vivem atualmente um momento de valorização institucional impulsionada pelos trabalhos de construção de novos currículos, iniciados em 2017, com o objetivo de adequá-los às diretrizes estabelecidas pelo Conselho Nacional de Educação (CNE) em 2015. Um grupo formado essencialmente por docentes especialistas na área de ensino de Física, fundamentado em consultas à comunidade universitária, elementos da literatura de pesquisa em ensino de Ciências, e de estudos de viabilidade, construiu profundas modificações nas matrizes curriculares. Indo ao encontro do que é preconizado pelo CNE, o novo currículo tem enfoque na construção de uma identidade própria para o curso de Licenciatura, promovendo a valorização do curso e a aproximação da escola básica. Novas disciplinas foram incorporadas (e.g., "Introdução à Física" e "Termoestatística para a Licenciatura") e remodelações em disciplinas já existentes foram realizadas.

Em decorrência desse contexto, os cursos de licenciatura do IF/UFRGS têm recebido mais atenção da instituição. Entre as ações que evidenciam essa valorização, destacam-se: $i$. O oferecimento de disciplinas em horários concentrados em um único turno para os licenciandos, proporcionando uma distribuição mais equilibrada de recursos para estudantes da licenciatura e do bacharelado; $i i$. O maior investimento de recursos humanos no curso, com a contratação de quatro novos docentes, possibilitando que mais disciplinas da licenciatura sejam ministradas por especialistas na área de ensino de Física, fomentando uma valorização do curso; iii. A realização 
de um projeto vinculado com o Programa de Apoio à Graduação da UFRGS, em que quatro monitores atuam na implementação de metodologias ativas de ensino nas disciplinas iniciais dos cursos; $i v$. A maior oferta de bolsas de iniciação científica especificamente voltadas para a área de pesquisa em ensino de Física; $v$. A valorização das atividades do Programa Institucional de Bolsas de Iniciação à Docência (PIBID) e o estabelecimento oferecimento de bolsas de Residência Pedagógica; e vi. A instituição de uma comissão de graduação específica para as licenciaturas.

Somadas às ações institucionais de valorização das licenciaturas, as ações do grupo de pesquisa-ação estabelecido na instituição também têm contribuído para a construção de um contexto favorável. Estudantes de graduação do grupo estão organizando atividades extraclasse voltados para os estudantes dos cursos de licenciatura. O "Fronteiras do Ensino de Física”, por exemplo, é um projeto em que estudantes das licenciaturas e do PPGEnFís se encontram quinzenalmente para debaterem sobre suas experiências ao longo do curso (e.g., atividades de pesquisa, ensino, extensão, estágios, discussões sobre temas atuais da área de Ensino de Física). O processo de apadrinhamento entre estudantes também está, com base na literatura da área (e.g., ZANIEWSKI; REINHOLZ, 2016), sendo reformulado pelos participantes do grupo, buscando fomentar relações entre veteranos e calouros que contribuam para a construção do senso de pertencimento dos licenciandos. Fundamentados nas ideias de Elliott (1991) sobre pesquisa-ação, os membros do grupo trabalham também em pesquisas em que procuram avaliar as atividades realizadas com o objetivo de coletar evidências que possam dirigir reformulações em novos ciclos de pesquisa-ação.

A disciplina "Introdução à Física" foi incorporada ao primeiro semestre dos cursos de licenciatura do IF/UFRGS no primeiro semestre de 2018. É uma disciplina com carga horária de 60 horas que envolve 30 calouros de licenciatura por semestre, contando ainda com o apoio de dois monitores que trabalham ativamente no delineamento e na implementação das atividades, constituindo a disciplina também em um espaço de formação para eles. Ainda que tenha entre seus objetivos amenizar as deficiências formativas da Educação Básica dos estudantes, o cerne das atividades desenvolvidas está na construção de sentido aos conteúdos de Física no contexto da formação de professores. Além disso, busca-se fomentar um aumento do senso de pertencimento dos estudantes a partir da construção de relações sociais colaborativas. No que segue, são detalhados os objetivos de ensino da disciplina. 


\section{Objetivos de Ensino}

O objetivo geral da experiência didática relatada neste artigo é delinear, implementar e avaliar uma disciplina introdutória em um curso de licenciatura em Física que fomente a motivação dos estudantes para persistir por meio da construção de crenças de autoeficácia, sensos de pertencimento e percepções de currículo mais positivas. Para se alcançar tal objetivo, foram traçados os seguintes objetivos específicos:

- Proporcionar que os licenciandos reflitam sobre o papel da educação científica e a natureza da Ciência, possibilitando que eles construam uma identidade fundamentada em uma concepção de ensino de Física voltada para a construção de criticidade, distanciando-se de visões do trabalho docente racionalistas técnicas, em que o professor supostamente transmite conhecimentos construídos em contextos desconectados da escola básica;

- Fomentar a construção de laços colaborativos entre os estudantes, promovendo a construção de unidade entre os estudantes de licenciatura, que influenciará as integrações social e acadêmica deles;

- Possibilitar que os estudantes construam sentido para os conceitos de Física e Matemática tratados no Ensino Médio, favorecendo a construção de competências para o enfrentamento de problemas de Física básica e a amenização de deficiências formativas da Educação Básica;

- Promover situações que possibilitem que os estudantes construam relações entre teorias científicas e a realidade, compreendendo o caráter representacional do conhecimento científico.

A disciplina "Introdução à Física" aborda conteúdos curriculares tanto vinculados com aspectos da formação de professores assim como relacionados com temas de Física e de Matemática básica. Entre os conteúdos priorizados vinculados com a formação de professores, destacam-se debates sobre: $i$. o papel da educação científica, ii. a natureza da Ciência, e iii. fundamentos teóricos ${ }^{2}$ subjacentes às metodologias ativas de ensino. Já os conteúdos de Física e Matemática básica priorizados são: $i$. Cinemática translacional e rotacional, $i i$. Dinâmica translacional e rotacional, iii. Princípios de conservação, $i v$. Trigonometria, vetores e álgebra básica, e $v$. Princípios de cálculo diferencial e integral.

Entre as metodologias ativas utilizadas, três delas se destacam, quais sejam: 
- Ensino sob Medida (ARAUJO; MAZUR, 2013): Com antecedência de alguns dias, são indicados materiais sobre conteúdos de Física, questões sobre a natureza da Ciência e/ou sobre o ensino de Física para que os estudantes leiam em horário extraclasse. É solicitado então que eles respondam, por meio de um formulário na plataforma de ensino a distância da UFRGS, algumas questões sobre essa leitura. A aula presencial é estruturada a partir do feedback fornecido pela turma, focando a discussão em aspectos essenciais em que os estudantes demonstraram dificuldades para compreender. A Figura 3 sintetiza os procedimentos previstos nessa metodologia. Salienta-se que as respostas dos estudantes são avaliadas em termos de empenho, e não em termos de adequação ao conhecimento científico. Com isso, busca-se fomentar um espaço para que os estudantes se sintam livres para expressarem seus pensamentos, o que é essencial para a efetividade da metodologia.

Figura 3: Representação esquemática da metodologia "Ensino sob Medida". É prevista a interação com um material (e.g., texto, vídeo, simulação computacional) antes da aula. O professor, ainda antes da aula, analisa as respostas dos alunos a questões sobre esse material e inicia a aula com uma discussão sobre essas respostas

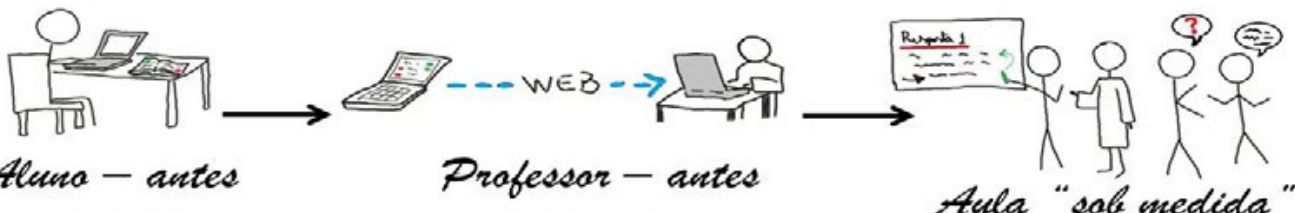

da aula

da aula

tula "sab medida"

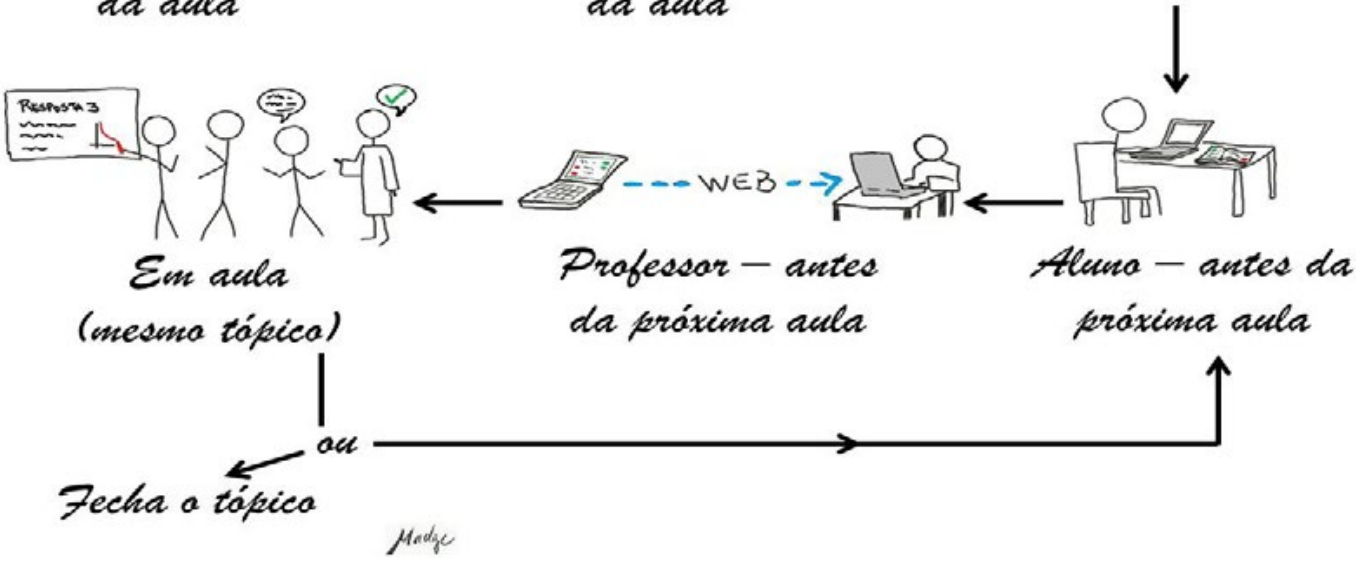

Fonte: ilustração de Madge Bianchi dos Santos. 
- Instrução pelos colegas (ARAUJO; MAZUR, 2013): São apresentadas questões conceituais de múltipla escolha e solicitado aos estudantes que votem na alternativa que julgam mais adequada. Essa votação é feita por meio de Plickers $^{3}$ (cartões de resposta individuais com códigos semelhantes a QR codes). Com base nessas respostas, mas ainda sem indicar qual é a alternativa mais adequada, o professor toma uma das seguintes três decisões: $a$. explica a questão e apresenta uma nova questão conceitual. Esse caso é escolhido se mais de 70\% dos estudantes chegarem na alternativa mais adequada; $b$. solicita que os estudantes procurem algum colega que votou em uma alternativa diferente da sua e que convença-o de que a sua alternativa é mais adequada. Após alguns minutos, repete o processo de votação e explica a questão, reiniciando o processo. Essa opção é escolhida se o percentual de acertos obtidos na primeira votação estiver entre $30 \%$ e $70 \%$; c. revisita o conceito abordado na questão por meio de uma exposição dialogada, colocando outra questão conceitual ao final da explanação e recomeçando o processo. Essa é a opção adotada se menos de 30\% das respostas estiverem corretas. A Figura 4 ilustra os procedimentos previstos na metodologia.

- Resolução de problemas abertos (OLIVEIRA; ARAUJO; VEIT, 2017): Baseado nos conhecimentos abordados na tarefa de leitura, o professor apresenta um problema em que: $a$. nem todos os elementos do evento envolvido são fornecidos; $b$. existem diferentes possibilidades de soluções; $c$. não são evidentes os conceitos e regras necessárias para a solução; $d$. referem-se a um contexto real; $e$. requer aplicação de estimativas e idealizações por parte dos estudantes. Em grupos, os estudantes realizam investigações experimentais, computacionais ou bibliográficas com o intuito de construir uma resposta ao problema proposto. As soluções encontradas são apresentadas aos colegas por meio de quadros brancos ${ }^{4}$ em uma discussão final. 
Figura 4: Representação esquemática da metodologia "Instrução pelos Colegas". As decisões do professor são pautadas pelos índices de acertos dos estudantes nas questões conceituais

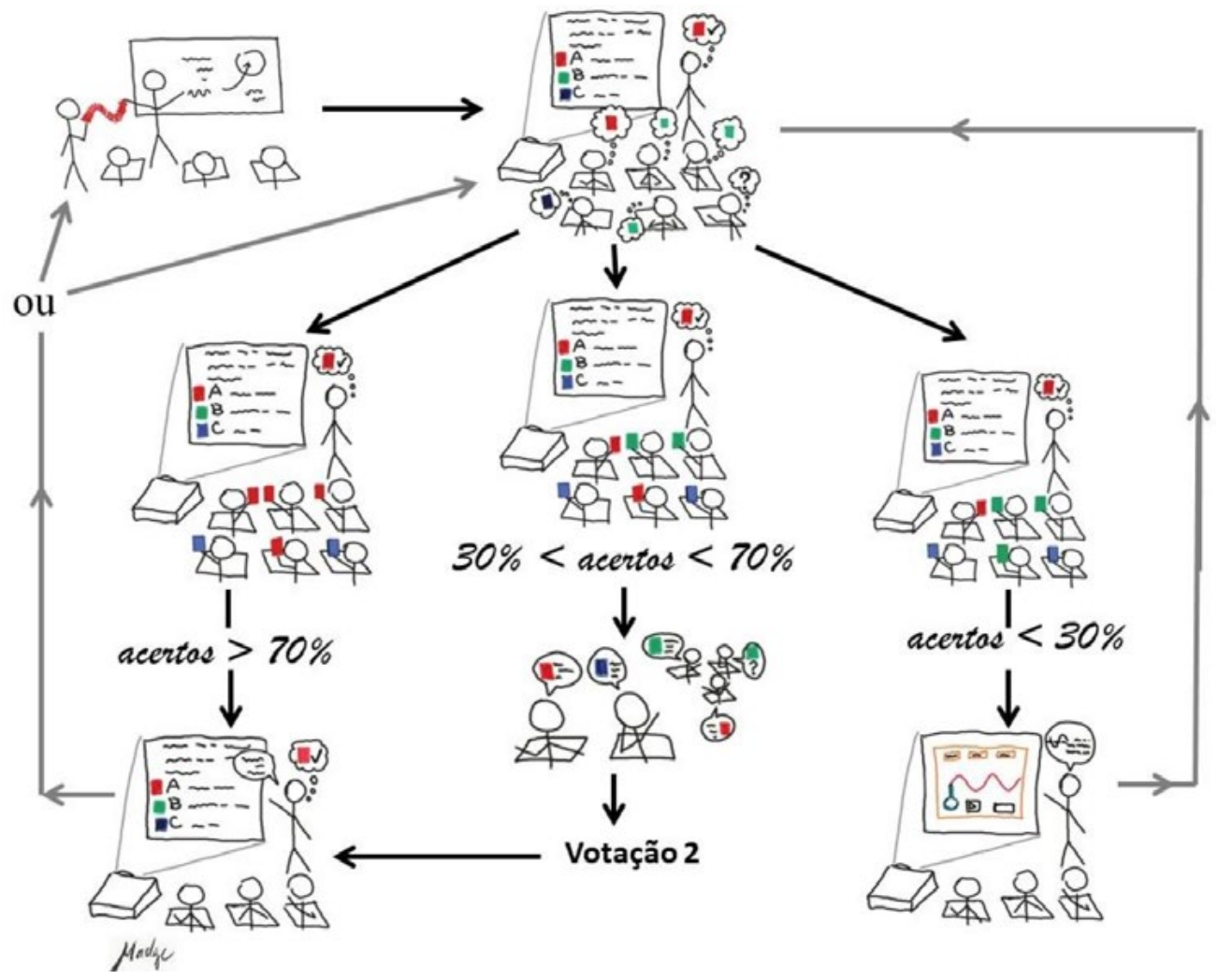

Fonte: extraído de SANTOS; ARAUJO; VEIT, 2016, p. 20.

Buscando fomentar a construção de concepções críticas sobre o trabalho docente, essas metodologias, além de serem implementadas em atividades, dirigem debates durante as aulas sobre a atividade docente. Por exemplo, ao se promover debates sobre a metodologia Ensino sob Medida, é discutido com os licenciandos sobre os elementos teóricos que fundamentam tal metodologia, que são centrados essencialmente na valorização do erro, no respeito às diferenças entre os estudantes no que se refere ao tempo para a construção de suas aprendizagens, e na concepção de que a aprendizagem ocorre a partir do que o sujeito já conhece. Sobre o Instrução pelos Colegas, é debatido que tal metodologia se fundamenta na concepção de processos argumentativos fomentam a aprendizagem, e que a compreensão conceitual precede o conhecimento operatório. Já sobre a resolução de problemas abertos, é ressaltado que tal metodologia está apoiada na concepção de que as situações dão sentido aos 
conceitos, que o fomento ao trabalho colaborativo é essencial para aprendizagem, e que o enfrentamento de problemas abertos, que demandam a tomada de decisão por parte dos estudantes é fundamental para que eles se tornem, gradativamente, competentes para mobilizar conhecimentos científicos em situações que extrapolam os muros da escola. Por meio desses debates, busca-se fomentar nos estudantes a construção de identidade e unidade, entendendo a formação do professor de Física como um processo único e distinto da formação de um bacharel. Essa perspectiva de formação, por conseguinte, contribui com a construção dos sensos de pertencimento dos estudantes enquanto licenciandos em Física.

Além disso, as atividades desenvolvidas na disciplina envolvem tanto elementos de Física quanto de Matemática básica, com o objetivo de amenizar deficiências formativas dos estudantes na Educação Básica, como conteúdos abordados em disciplinas iniciais dos cursos de licenciatura em Física, possibilitando que eles atribuam sentido para estes conteúdos. Busca-se assim, além de fomentar a construção de crenças de autoeficácia mais positivas, decorrentes do aprofundamento dos seus conhecimentos sobre Física e Matemática, proporcionar percepções de currículo mais adequadas, possibilitando que eles compreendam a lógica subjacente ao currículo. As atividades desenvolvidas sobre cinemática e dinâmica, por exemplo, envolvem conteúdos de disciplinas de Matemática como Cálculo Diferencial e Integral, ainda que de forma essencialmente conceitual, dando sentido para a aprendizagem desses temas. No que segue, são expostos os procedimentos didáticos implementados.

\section{Procedimentos Didáticos}

Resumidamente, a disciplina "Introdução à Física" tem sido desenvolvida por meio de três sequências que englobam quatro modalidades de atividades, quais sejam: $i$. uma tarefa de leitura (Ensino sob Medida); ii. uma atividade investigativa contextualizada e problematizada a partir de elementos mobilizados na tarefa de leitura (Resolução de Problemas Abertos); iii. uma seção em que os estudantes debatem questões sobre conceitos evocados durante a atividade investigativa (Instrução pelos Colegas); e $i v$. uma atividade computacional pautada por uma situação contextualizada e problematizada (Resolução de Problemas Abertos). Cada sequência demanda entre oito e doze aulas com duração de 1h30min. Para exemplificar uma dessas sequências, expomos aqui alguns elementos da primeira série de atividades da 
disciplina, centrada em situações da cinemática. Alinhada com a metodologia Ensino sob Medida (ARAUJO; MAZUR, 2013), ela começa com uma tarefa de leitura sobre as objeções mecânicas ao modelo heliocentrista que motivaram a construção de uma nova Mecânica por Galileo Galilei. Mais precisamente, é solicitado que os estudantes, em horário extraclasse, lessem um resumo das duas primeiras seções do artigo "Três episódios de descoberta científica: da caricatura empirista a uma outra história”, de Silveira e Peduzzi (2006). A problematização da atividade é fundamentada, então, nas respostas dos estudantes para duas questões respondidas previamente sobre a leitura realizada. Uma das questões, por exemplo, é: Qual(ais) era(m) o(s) principal(is) objetivo(s) de Galileu com a sua teoria sobre a queda dos graves?

Começa-se fazendo uma discussão sobre o papel da educação científica fomentada pela apreciação de uma filmagem de uma palestra que trata sobre pseudociências e a falta de diálogo entre cientistas e a sociedade ${ }^{5}$. A discussão é encaminhada para um questionamento: Qual é o papel da educação científica na construção da criticidade da sociedade perante as pseudociências? São expostos alguns temas que são consensuais entre cientistas, mas que levantam debates em meio à sociedade como, por exemplo, a ação antrópica nas mudanças climáticas e o papel da Mecânica Quântica em efeitos espirituais. Por fim, destaca-se que uma das mais recentes pseudociências que vem ganhando destaque nos meios sociais é o terraplanismo.

Como é destacado na tarefa de leitura realizada pelos estudantes, Galileo contrapôs uma série de objeções mecânicas ao modelo heliocentrista. Os argumentos da torre e do canhã $0^{6}$, por exemplo, foram temas dos debates travados nos livros do cientista. Faz-se, então, um paralelo entre o momento vivido por Galileo e o atual, destacando que os defensores do terraplanismo utilizam argumentos semelhantes aos usados pelos que atacavam as ideias de Galileo. Partindo das respostas dos estudantes à tarefa de leitura, mostra-se que Galileo se fundamentava em argumentos metafísicos em suas teorias, e que um pressuposto importante dos seus trabalhos era o da independência de movimentos. Destaca-se, então, que, para contrapormos diversos dos argumentos dos terraplanistas, precisamos também nos fundamentar nesse mesmo princípio de Galileo.

Promovendo a resolução de um problema aberto, a problematização da atividade é realizada a partir da seguinte questão: Suponha que um estudante de Ensino Médio questione o princípio de independência de movimentos de Galileu, afirmando que não acredita nesse pressuposto e que entende que a Terra é plana, como você argumentaria com esse estudante? Construir suporte empírico para o pressuposto 
de Galileo passa a ser o objetivo dos estudantes na atividade. Solicita-se que eles se coloquem no papel de um docente, que pretende fomentar a criticidade de um estudante da Educação Básica debatendo sobre a validade dos princípios da Física, em particular, do da independência dos movimentos de Galileo, usando argumentos teóricos e dados empíricos. Os estudantes, em grupos construídos em sorteio, delineiam, executam a analisam experimentos que envolvem a coleta de dados utilizando o software Tracker ${ }^{7}$ para amparar seus argumentos.

Durante todo esse processo de investigação, os estudantes vivem experiências que demandam debates na busca pela construção de soluções para os problemas propostos ou gerados durante a atividade, o que fomenta o estabelecimento de relações sociais colaborativas, possibilitando um aumento no senso de pertencimento dos estudantes na Universidade, e de experiências de sucesso na resolução de problemas, possibilitando um aumento nas suas crenças de autoeficácia para enfrentarem as situações das disciplinas de Física básica. O enfoque na história de Galileo possibilita ainda a construção de uma concepção epistemológica mais sofisticada por parte dos estudantes, ou seja, de uma perspectiva de Ciência como uma atividade essencialmente humana, o que, segundo estudos recentes (e. g., KAPUCU; BAHÇIVAN, 2015), estão positivamente associadas com as crenças de autoeficácia dos estudantes para resolverem problemas científicos e com as suas atitudes em relação à Ciência.

A primeira atividade da sequência exemplificada aqui, que transcorre durante quatro aulas de 1h30mim, encerra-se com uma apresentação dos grupos dos resultados alcançados com suas investigações com o uso de pequenos quadros brancos aos colegas. Esse é um momento de intenso debate, em que o professor atua como mediador e os estudantes procuram expor seus argumentos e dirimir suas dúvidas sobre as investigações dos colegas. Sawtelle et al. (2012) mostram que atividades desenvolvidas com a metodologia Modeling Intruction, que preconiza um ensino centrado na representação de eventos reais e na aprendizagem colaborativa centrada no aluno, de modo semelhante ao estabelecido na primeira atividade, favorecem que os estudantes tenham experiências que promovem crenças de autoeficácia mais positivas. É esperado que, além disso, tais atividades favoreçam a construção de um senso de pertencimento em função das relações sociais construídas durante o trabalho colaborativo. A Figura 5 ilustra o momento de debate que ocorre ao final das atividades investigativas. 
Figura 5: Apresentações dos resultados de investigação com pequenos quadros brancos ${ }^{8}$

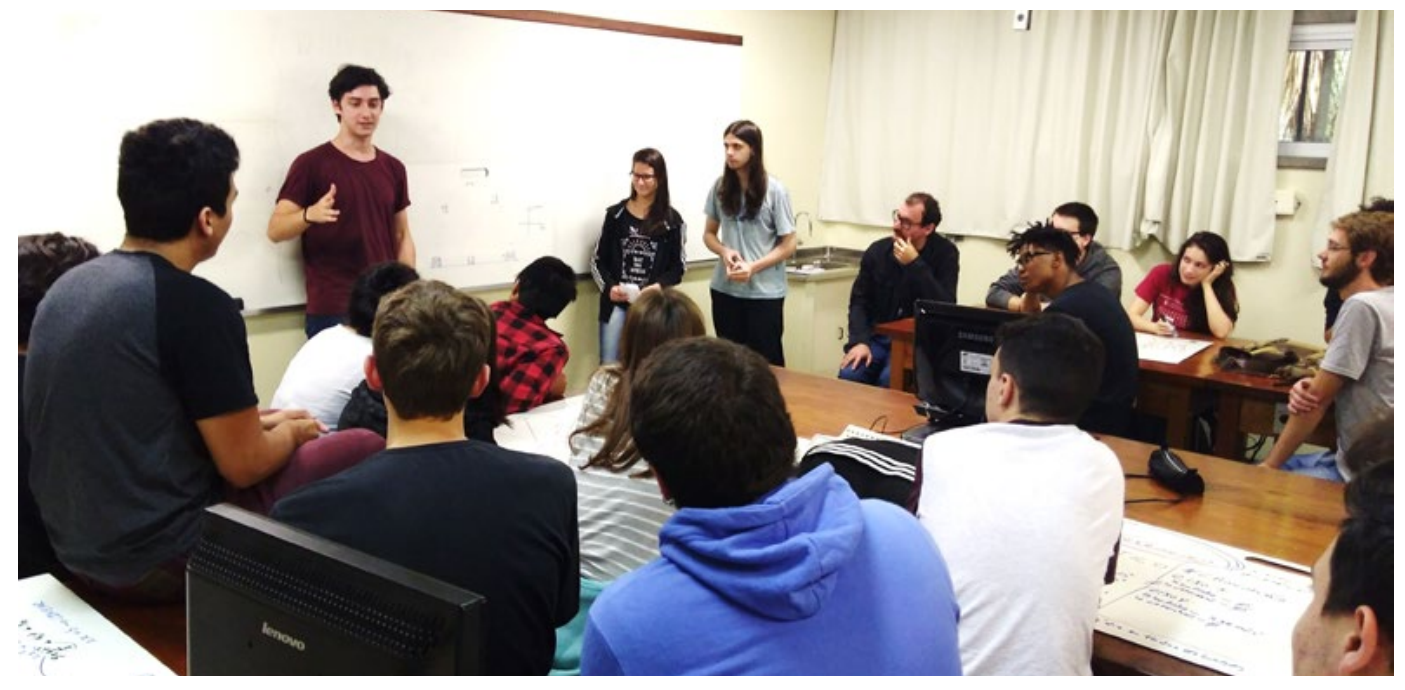

A aula seguinte é conduzida inteiramente com a metodologia Instrução pelos Colegas (ARAUJO; MAZUR, 2013) com questões sobre gráficos da cinemática, promovendo frequentes interações entre os estudantes, favorecendo a construção de laços colaborativos. A seguir, é apresentada uma questão que é utilizada na implementação dessa metodologia (extraída de ARAUJO, 2002).

O gráfico abaixo descreve o movimento de um objeto. Qual sentença representa uma interpretação correta desse movimento?

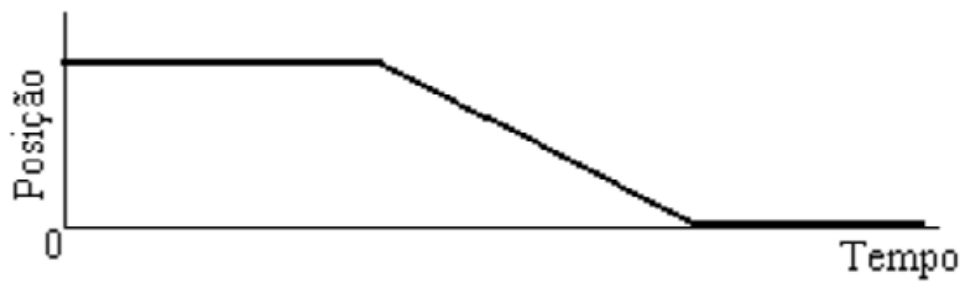

a. O objeto rola ao longo de uma superfície plana. Então ele desce um plano inclinado e finalmente pára.

b. O objeto inicialmente não se move. Então ele desce um plano inclinado e finalmente pára.

c. O objeto está se movendo com velocidade constante. Então ele diminui sua velocidade e pára.

d. O objeto inicialmente não se move. Então ele se move e finalmente pára. 
A literatura evidencia que esse método, assim como o Ensino sob Medida, favorecem a construção de crenças de autoeficácia mais positivas (ESPINOSA, 2016). Gok (2012), por exemplo, argumenta que o sucesso do Instrução pelos Colegas para melhorar as crenças de autoeficácia do indivíduo se deve, possivelmente, aos estudantes receberem constante feedback sobre o resultado de seus esforços nas atividades. Já Down, Araujo e Mazur (2015) relacionam a construção de crenças de autoeficácia mais positivas dos estudantes com o engajamento cognitivo deles nas respostas às questões das tarefas de leitura das atividades com Ensino sob Medida. A Figura 6 ilustra um momento de votação realizada com o aplicativo Plickers.

Figura 6: Estudantes votando durante a implementação da metodologia "Instrução pelos Colegas"

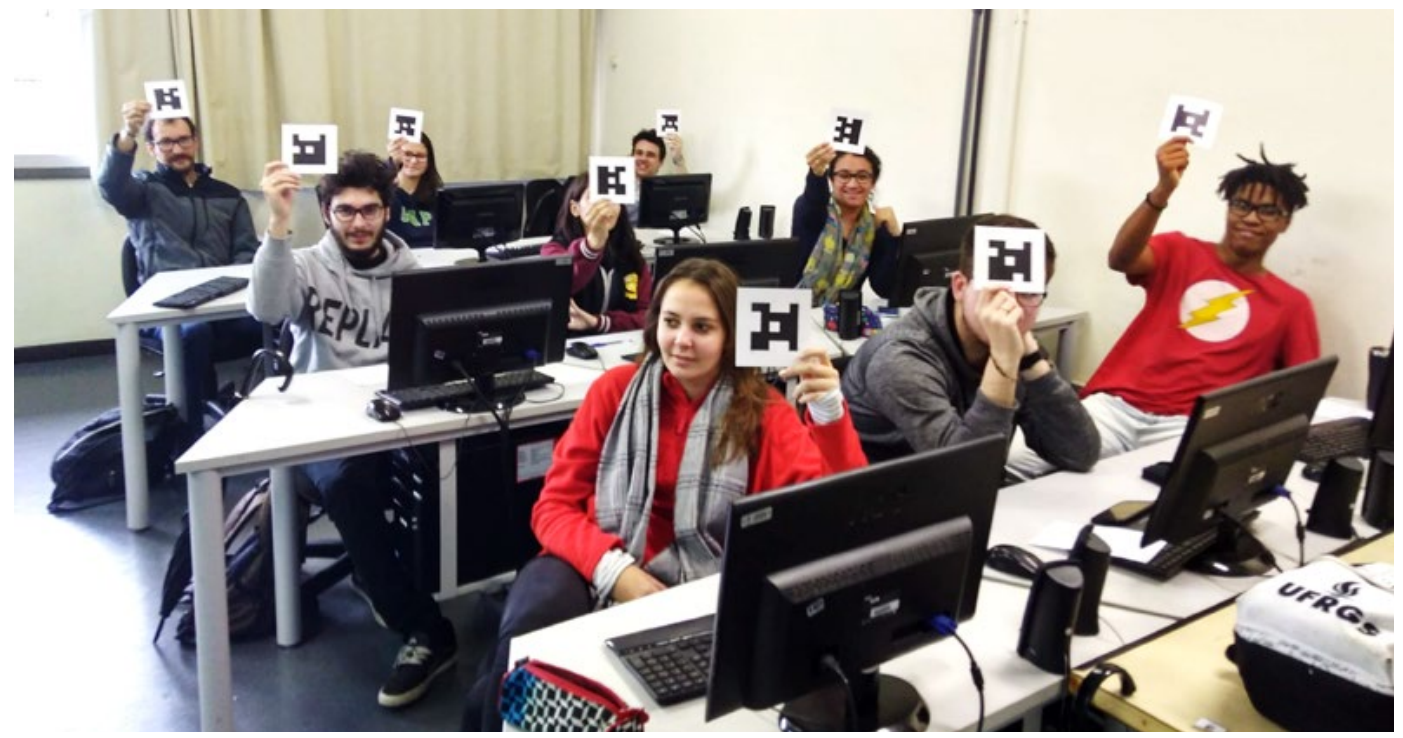

Por fim, na última aula da sequência didática, é solicitado que os estudantes, em duplas, construam um modelo computacional com o software Modellus ${ }^{9}$ representando o movimento de um projétil lançado obliquamente. Procurando fomentar a resolução de um problema aberto, a problematização dessa atividade é inspirada no trabalho de Silva e Fumiã (2018), sendo conduzida a partir da seguinte questão: É seguro disparar um revólver orientado para cima? Novamente, busca-se promover a construção de relações sociais colaborativas e, consequentemente, um maior senso de pertencimento dos estudantes à Universidade durante tal atividade. Além disso, na construção do modelo computacional para se responder a questão problemati- 
zadora, são usadas equações que envolvem cálculo diferencial, possibilitando que os alunos atribuam sentido às disciplinas cursadas no início do curso e, portanto, construam percepções de currículo mais positivas. Por fim, essa atividade demanda a mobilização de conceitos que foram usados na investigação sobre a independência de movimentos, promovendo uma amenização das deficiências formativas dos estudantes.

Em suma, a expectativa que se tem com a disciplina "Introdução à Física" é que ela, concatenada com outras ações institucionais, contribua para que os estudantes construam crenças de autoeficácia mais altas, desenvolvam um senso de pertencimento maior e uma percepção de currículo mais positiva, fomentando a motivação dos estudantes em persistir no curso de licenciatura em Física. Como foi argumentado com a sequência didática exemplificada, tal expectativa é fundamentada em resultados da literatura e em hipóteses estabelecidas no planejamento da disciplina. Por exemplo, espera-se que a percepção de currículo dos estudantes seja mais positiva na medida em que eles, já em "Introdução à Física", tenham maior contato com debates particularmente vinculados com a área de pesquisa em ensino de Física, favorecendo a construção de uma identidade própria para o curso de licenciatura. Antes da implementação dessa disciplina, os estudantes realizavam tais debates apenas em disciplinas da Faculdade de Educação até meados do curso, disciplinas essas que são realizadas com alunos dos mais diversos cursos da Universidade. Desse modo, durante os primeiros semestres do curso, que é quando ocorrem os maiores índices de evasão, os estudantes tinham limitadas discussões que fossem dirigidas às particularidades do Ensino de Física.

\section{Avaliação da Aprendizagem na Disciplina "Introdução à Física"}

É fundamental em qualquer processo educativo formal que a avaliação da aprendizagem seja coerente com os procedimentos de ensino. Pautados por isso, optamos por, na disciplina "Introdução à Física", centrar a avaliação em aspectos conceituais, alinhando-se assim aos fundamentos teóricos que sustentam a disciplina. Entendemos ainda que a avaliação deve facilitar a regulação dos processos de aprendizagem (MOREIRA, 2003). Essa regulação depende do uso de uma série de conhecimentos metacognitivos que possibilitam que o estudante controle suas ações 
com o intuito de alcançar um objetivo preestabelecido. Por isso, optamos por usar os instrumentos de avaliação como recursos para fomentar o conhecimento metacognitivo, trazendo à consciência dos estudantes suas limitações e potencialidades. Por fim, cientes de que a literatura tem apontado que a avaliação essencialmente centrada em provas pode fomentar a diminuição das crenças de autoeficácia dos estudantes (e.g., ESPINOSA, 2016), optou-se por diminuir o peso que tradicionalmente se atribui à prova na avaliação da aprendizagem da disciplina "Introdução à Física”. Tal avaliação é prioritariamente realizada por meio de relatórios das atividades investigativas ( $40 \%$ da nota final), análises do empenho na tarefa de leitura ( $20 \%$ da nota final), e de duas provas ( $40 \%$ da nota final).

Os relatórios de investigação são avaliados em termos da coerência das investigações realizadas. Em uma das primeiras aulas da disciplina, os alunos são orientados sobre os elementos que compõem um bom relatório, destacando aspectos epistemológicos subjacentes a sua estrutura. Por exemplo, é destacado que não é adequado redigir o relatório propondo que um experimento foi realizado para se provar uma lei, pois tal concepção é epistemologicamente ultrapassada (SILVEIRA; PEDUZZI, 2006). É proposto então que o relatório traga como viés epistemológico a noção de que uma hipótese foi contrastada, demandando uma construção teórica precedente ao trabalho experimental.

Em uma das atividades investigativas, os estudantes são convidados a avaliar as apresentações de resultados dos colegas, possibilitando que eles assumam uma postura de avaliadores da aprendizagem, proporcionando um momento de construção de identidade docente. Espera-se que desse modo a atividade contribua para um aumento em seus sensos de pertencimento. As notas atribuídas pelos colegas são incorporadas à nota do relatório da investigação. Nessa mesma atividade, os veteranos do curso são convidados a assistirem às apresentações dos trabalhos e a contribuírem com sugestões para que os calouros aprimorem suas investigações. Essa participação dos veteranos na disciplina também é planejada como uma ação para promover relações entre os estudantes do curso, fomentando a integração social dos calouros e, portanto, o aumento de seus sensos de pertencimento.

Avaliando as tarefas de leitura por empenho, busca-se construir um ambiente de liberdade de expressão de tal modo que o docente da disciplina possa ter contato com as verdadeiras ideias dos estudantes. Parte-se do pressuposto de que a avaliação em termo da adequação com o conhecimento científico leva os estudantes a terem 
receio de apresentarem seus raciocínios. Não se trata aqui de se desprezar o rigor científico na avaliação, mas sim de possibilitar que eles respondam sem a pressão de ter o seu pensamento reprovado.

Alinhando as provas com os procedimentos didáticos implementados na disciplina, optamos por centrá-las em aspectos conceituais e avaliá-las em termos da qualidade da argumentação apresentada. O seguinte enunciado é exposto no topo das duas provas da disciplina: "Em cada uma das questões, apresente a sua resposta e a justifique. A avaliação será realizada por meio da análise da qualidade dos argumentos expostos". Além disso, procurando fomentar um aumento no senso de pertencimento dos estudantes por meio da construção da identidade docente, as provas envolvem questões em que o estudante é posto na posição de um professor. A seguinte questão exemplifica uma dessas questões:

\footnotetext{
Suponha que você esteja na posição de professor de Física em uma turma de estudantes de Ensino Médio. Quais temas e/ou metodologias explorados na disciplina "Introdução à Física" poderiam ser transpostos para as suas aulas? De que modo? Responda esclarecendo que conteúdos seriam abordados, explicando os conceitos e leis explorados. Destaque também o(s) motivo(s) pelo(s) qual(is) consideras que tais conteúdos devem ser abordados no Ensino Médio, explicando como entendes que eles podem ser relevantes para os estudantes.
}

$\mathrm{Na}$ aula seguinte à prova, todas as questões conceituais são debatidas com o grande grupo com o uso de experimentos e simulações computacionais, quando necessário. Busca-se, nesse debate, tornar o processo avaliativo em um procedimento formativo, possibilitando que os estudantes construam conhecimentos sobre suas próprias limitações e potencialidades.

\section{Uma Análise Preliminar dos Primeiros Resultados}

Compreender os processos envolvidos na decisão dos estudantes de evadir ou de persistir em um curso de graduação é um grande desafio. Neste artigo, nos amparamos na literatura para, ao mesmo tempo, implementar e investigar uma ação focada no fomento à persistência. Essa perspectiva nos motivou a estabelecer um grupo de pesquisa-ação sobre evasão no IF/UFRGS que, englobando as ações relatadas na disciplina "Introdução à Física", vem realizando estudos para promover um acompanhamento da trajetória dos estudantes dos cursos de licenciatura. Por isso, a avaliação que apresentamos aqui não é limitada à visão de um professor 
que implementou metodologias inovadoras em suas aulas; é pautada por debates e investigações desenvolvidas em um grupo, ou seja, no âmago de uma comunidade que pretende transformar o curso de licenciatura do IF/UFRGS para torná-lo mais acolhedor e alinhado com uma perspectiva de formação profissional crítica, em que teoria e prática caminhem lado a lado. Desse modo, a discussão que segue é fundamentada tanto pelos registros do professor da disciplina como por manifestações dos estudantes em questionários e entrevistas realizadas no âmbito das investigações desse grupo de pesquisa-ação. Essencialmente, os dados são oriundos de um questionário e do diário de bordo de um estudante de mestrado que está investigando a influência das experiências de primeiro semestre dos ingressantes nos cursos de licenciatura em Física do IF/UFRGS. Foge do escopo deste artigo a apresentação de resultados do grupo de pesquisa-ação; nos centramos na exposição de um relato de experiência bem fundamentada teoricamente e centrada em um importante problema: a evasão nos cursos de graduação em Física.

Ainda que uma avaliação mais precisa da disciplina demande um acompanhamento de maior prazo, pudemos concluir que ele contribuiu para fomentar a motivação dos estudantes para persistir. Pudemos coletar depoimentos que mostram que a disciplina "Introdução à Física", no formato em que foi implementada, foi fundamental para que calouros se mantivessem no curso de graduação. A seguinte manifestação de um estudante exemplifica um desses depoimentos: "O que eu sempre falei com os meus amigos, é que um monte de pessoas fala que teria saído se não fosse a cadeira de introdução". Outro estudante complementou: "Eu posso até falar que, se não fosse pela matéria 'Introdução à Física', eu já teria desistido do curso".

Um dos motivos que explica esse impacto da disciplina está no fato de que ela promoveu uma melhor percepção de currículo entre os estudantes, como é demonstrado pela seguinte manifestação de um estudante: "A aula de 'Introdução à Física', na verdade, mostrou porque geometria analítica e cálculo são necessários [...] meio que mostrou o porquê de tu ter que aprender. Isso meio que me motivou a aprender vetores, por exemplo". Outro complementou: "Ainda que introdução tenha tido enfoque na parte conceitual, o professor deu algumas aulas em que ele falava 'aqui faz uma derivada'... Ele usou muito vetores também”.

Depoimentos dos estudantes evidenciam ainda que a interação social fomentada pela implementação de atividades centradas no trabalho colaborativo foram essenciais para que eles pudessem se integrar socialmente. Em uma entrevista, um 
estudante, que declarava que começou a se sentir integrado socialmente no decorrer das experiências do primeiro semestre, atribuiu tal integração às aulas de "Introdução à Física”. Ele disse: "Foi nas aulas de 'Introdução'. Aquela coisa do Instrução pelos Colegas... Porque daí eu tinha que conversar com as pessoas. [...] Eu não conversaria com as pessoas se eu não fosse obrigada. E aí depois eu fui me acostumando".

Pudemos identificar também que a atenção pedagógica, entendida aqui como a preocupação do professor com a aprendizagem dos estudantes, é vista como algo fundamental pelos calouros. As manifestações deles mostram que, ao constatarem o cuidado do professor em preparar as atividades considerando as dificuldades dos estudantes, sentiram-se valorizados, evidenciando que tiveram um aumento em suas percepções de currículo. Um estudante disse: "Atualmente a minha cadeira favorita é 'Introdução à Física', pois percebo que o professor se preocupa se eu estou aprendendo ou não". Outro estudante disse: "São aulas em que o professor se interessa pelo aprendizado do aluno, assim como se interessam pela permanência do aluno".

Outro resultado notável com a disciplina envolve a contribuição das atividades para que os calouros refletissem sobre as ações necessárias às práticas docentes, a exemplo da contextualização da atividade investigativa sobre a queda dos graves, favorecendo a construção de uma identidade docente. Em suas falas, os calouros evidenciaram que o contato com novas metodologias de ensino, com debates sobre os fundamentos teóricos da pesquisa em ensino de Física, e a perspectiva de ser agente ativo em transformações sociais foram fundamentais para que persistissem no curso. Um estudante disse: "Acho que as aulas de introdução, motivando a gente a pensar como professor, me deu uma visão diferente. O contato com o pessoal da pós-graduação... Isso fez a gente ver que o ensino de Física não é algo chato; é algo interessante". Outro estudante, que no início do curso afirmava que cursava licenciatura apenas para ingressar futuramente em um curso de engenharia, explicou que, após as experiências de primeiro semestre, passou a desejar ser professor de Física. Questionado sobre os motivos disso, afirmou: "Foi por perceber que um professor é muito importante, sabe? As aulas da introdução foram as que me fizeram mudar bastante de opinião".

Ainda que a disciplina tenha sido avaliada de forma muito positiva, pudemos identificar limitações em seus resultados em decorrência da dificuldade enfrentada para se legitimar os processos de avaliação da aprendizagem implementados e do enfoque na compreensão conceitual de conteúdos majoritariamente já abordados 
no Ensino Médio. O seguinte depoimento ilustra isso: "Eu sinto que introdução não é Física. E isso é uma opinião só minha. Até falei sobre isso com várias pessoas, e as pessoas diziam 'Ah! Mas introdução é legal!'. Mas, para mim, não é Física. [...] Parece que entre eu e um aluno de Ensino Médio, a gente sabe a mesma coisa".

\section{Considerações finais}

Identificar nas falas dos estudantes que as ações realizadas na disciplina "Introdução à Física" foram decisivas para suas formações e que elas promoveram uma ressignificação da atividade docente é bastante recompensador para os autores deste artigo. A decisão de centrar esse projeto em cursos de licenciatura não é apenas contextual, é também pautada pela convicção de que a formação de professores deve ser tratada com prioridade, e que essa formação demanda reflexões sobre a própria identidade que queremos construir. Ações como as desenvolvidas na disciplina "Introdução à Física" possibilitam que os estudantes, a partir do exemplo, possam refletir criticamente sobre o trabalho docente, representando-o como algo muito mais complexo do que um trabalho resumido a um conjunto de ações dirigidas a uma suposta transmissão de conteúdos. Ao enfrentarem as situações construídas na disciplina "Introdução à Física", os alunos podem entender o professor como um ser criativo, que precisa inovar a cada dia em suas práticas e que, refletindo sobre elas, constrói e reconstrói conhecimentos.

Neste artigo, nos restringimos à exposição de um relato de experiência de uma disciplina para calouros dos cursos de licenciatura em Física. Foge do escopo deste trabalho a apresentação de resultados de pesquisas realizadas nessa implementação. Investigações estão em andamento nesse contexto e artigos com os resultados alcançados serão submetidos para publicação em breve. O objetivo deste trabalho em particular está focado na exposição de uma alternativa didática bem fundamentada teoricamente, pautada pelo uso de metodologias ativas de ensino e por resultados da literatura da área de ensino de Ciências, para a promoção da persistência dos estudantes em cursos de licenciatura em Física. Indo além de outras alternativas presentes na literatura, que se baseiam na concepção de que o uso de métodos ativos de ensino promove a permanência dos estudantes essencialmente em função de melhores resultados de aprendizagem, evidenciamos como tais métodos se relacionam também com outros determinantes da decisão de evadir ou de persistir segundo 
Tinto (2017), como o senso de pertencimento, a percepção de currículo e as crenças de autoeficácia (MORAES; ESPINOSA; HEIDEMANN, 2019).

Cabe salientar que não assumimos a concepção de que mudanças nas metodologias de ensino empregadas nas disciplinas de cursos de graduação são suficientes como ações institucionais de combate à evasão. Ainda que, como mostramos, métodos ativos de ensino tenham potencial para fomentar a persistência, é importante considerar outros fatores que podem favorecer a evasão, mas que não estão ao alcance dos métodos de ensino. Amparo psicológico, bolsas e auxílio financeiro, por exemplo, podem ser elementos fundamentais para motivar o graduando a prosseguir em seus estudos. Neste artigo, no entanto, defende-se que essas ações, mesmo sendo fundamentais em programas institucionais de combate à evasão, não podem ser desacompanhadas da construção de uma sala de aula mais acolhedora e significativa para os estudantes. Grande parte das interações realizadas por eles acontece nesse ambiente. Por isso, é fundamental que, principalmente nos primeiros anos de curso, quando ocorrem os maiores índices de evasão, seja promovida uma superação dos tradicionais métodos de ensino que costumeiramente fomentam a passividade dos estudantes em situações com pouco significado.

\section{Dropout or persist? An introductory subject focused on fostering persistence in a physics teacher training course}

\section{Abstract}

A great problem on Brazilian educational system are the high dropout rates of physics undergraduate courses. Graduation cerimonies with less than ten students are frequent in these courses. On the other hand, there is a huge lack of physics teachers in schools. Therefore, actions focused in decreasing of the dropout rates are fundamental. In this article, we report an action that is being developed in an introductory subject of a physics teacher training course in the Universidade Federal do Rio Grande do Sul (UFRGS) with the objective of fostering students' motivation to persist in the courses. Based on Vincent Tinto's Model of Student Motivation and Persistence, we developed activities designed to improve students' perceptions of: $i$. their ability to cope demands of the course (self-efficacy beliefs); ii. their belonging as members of a community that values their participation in the institution (sense of belonging); and iii. the value and/or relevance of the envisaged studies in their course curriculum (perception of curriculum). The evaluation of the discipline shows that it has motivated students to persist, promoting among them the construction of a teaching identity, a conceptual understanding of theories of physics, and the establishment of relationships between the contents provided in the curriculum.

Keywords: active learning methods, dropout, physics undergraduate courses. 
1 Uma versão preliminar deste trabalho foi apresentada no XXIII Simpósio Nacional de Ensino de Física, em Salvador, Bahia, em 2019.

2 Não argumentamos em favor da articulação de referenciais teóricos de aprendizagem aos métodos ativos de ensino. Mobilizamos aqui uma acepção de "fundamentos teóricos" em seu sentido mais amplo, ou seja, enquanto conjunto de asserções que sustentam, dirigem e organizam os métodos ativos de ensino em função dos seus objetivos.

3 Plickers é um aplicativo para a realização de votações em salas de aula em que os estudantes levantam cartões com estruturas semelhantes aos QR Codes para indicarem suas opções em questões objetivas que são lidas pelo aplicativo com o uso da câmera de um celular. Mais detalhes podem ser consultados em: https://www.plickers.com. Acesso em: 10/10/2019.

4 O uso de pequenos quadros brancos é inspirado na metodologia de ensino denominada Modeling Instruction, de David Hestenes. Mais detalhes podem ser consultados em: https://modelinginstruction.org/. Acesso em: 30/07/2019.

5 Palestra proferida pela prof. Natália Pasternak no TEDx USP disponibilizada em: https://www.youtube. com/watch?v=F3kUeDlP3Io. Acesso em: 30 de junho de 2019.

6 Os céticos em relação ao heliocentrismo argumentavam que, se um objeto é abandonado do alto de uma torre e a Terra gira, ele não poderia atingir sua base, pois a Terra rotaria enquanto o objeto está em queda. Argumento semelhante é usado quando se defendida que, se a Terra gira, uma bola lançada por um canhão deveria alcançar distâncias diferentes dependendo da direção que ela era lançada.

7 O Tracker é um software livre para a realização de videoanálise de eventos físicos. Disponível em: https:// physlets.org/tracker/. Acesso em: 30 de junho de 2019.

8 Os participantes assinaram um termo de consentimento esclarecido autorizando o uso de suas imagens para fins acadêmicos.

9 O Modellus é um software multiplataforma de modelagem computacional. Disponível em: http://www. modellus.pt/. Acesso em: 30 de junho de 2019.

\section{Referências}

ARAUJO, Ives Solano. Simulação e modelagem computacionais como recursos auxiliares no ensino de física geral. 2005. 229 f. Dissertação (Mestrado em Ensino de Física) - Instituto de Física, Universidade Federal do Rio Grande do Sul, Porto Alegre, 2005. Disponível em: https:// lume.ufrgs.br/handle/10183/5771. Acesso em: 13 out. 2019.

ARAUJO, Ives Solano; MAZUR, Eric. Instrução pelos colegas e ensino sob medida: uma proposta para o engajamento dos alunos no processo de ensino-aprendizagem de Física. Caderno Brasileiro de Ensino de Física, v. 30, n. 2, p. 362-384, ago. 2013. DOI: https://doi.org/10.5007/ 2175-7941.2013v30n2p362.

BANDURA, Albert. Self-efficacy: The exercise of control. New York: W. H. Freeman, 1997.

BRAGA, Mauro Mendes; PEIXOTO, Maria do Carmo Lacerda; BOGUTCHI, Tânia Fernandes. A evasão no ensino superior brasileiro: o caso da UFMG. Avaliação: Revista da Rede de Avaliação Institucional da Educação Superior, Campinas, v. 8, n. 3, p. 161-189, mai. 2003. Disponível em: http://periodicos.uniso.br/ojs/index.php/avaliacao/article/view/1237. Acesso em: 13 out. 2019.

BRASIL. Universidade Federal do Rio Grande do Sul. UFRGS permanece como a melhor universidade federal no Índice Geral de Cursos. 2018a. Disponível em: http://www.ufrgs. 
br/ufrgs/noticias/ufrgs-permanece-como-a-melhor-universidade-federal-no-indice-geral-de-cursos. Acesso em: 13 out. 2019.

BRASIL. Universidade Federal do Rio Grande do Sul. Ranking aponta UFRGS entre as 10 melhores universidades da América Latina. 2018b. Disponível em: http://www.ufrgs. br/ufrgs/noticias/ranking-aponta-ufrgs-entre-as-10-melhores-universidades-da-america-latina. Acesso em: 13 out. 2019.

CASTRO, Alexandre Kurtz dos Santos Sisson de. Evasão no Ensino Superior: um estudo no curso de psicologia da UFRGS. 2012. 118 f. Dissertação (Mestrado em Psicologia) - Instituto de Psicologia, Universidade Federal do Rio Grande do Sul, Porto Alegre, 2012. Disponível em: https://ume.ufrgs.br/handle/10183/55077. Acesso em: 13 out. 2019.

DAITX, André Cristo; LOGUERCIO, Rochele de Quadros; STRACK, Ricardo. Evasão e retenção escolar no curso de licenciatura em química do Instituto de Química da UFRGS. Investigações em Ensino de Ciências, v. 21, n. 2, p. 153-178, ago. 2016. Disponível em: https://www.if.ufrgs. br/cref/ojs/index.php/ienci/article/view/111. Acesso em: 13 out. 2019.

DOWD, Jason E.; ARAUJO, Ives Solano; MAZUR, Eric. Making sense of confusion: Relating performance, confidence, and self-efficacy to expressions of confusion in an introductory physics class. Physical Review Special Topics - Physics Education Research, v. 11, n. 1, p. 1-10, mar. 2015. DOI: http://dx.doi.org/10.1103/PhysRevSTPER.11.010107.

ELLIOTT, John. El cambio educativo desde la investigación-acción. Madrid: Ediciones Morata, 1991.

ESPINOSA, Tobias. Aprendizagem de Física, trabalho colaborativo e crenças de autoeficácia: um estudo de caso com o método Team-based Learning em uma disciplina introdutória de eletromagnetismo. 2016. 208 f. Dissertação (Mestrado em Ensino de Física) - Instituto de Física, Universidade Federal do Rio Grande do Sul, Porto Alegre, 2016. Disponível em: https:// lume.ufrgs.br/handle/10183/135013. Acesso em: 13 out. 2019.

GOK, Tolga. The effects of peer instruction on students' conceptual learning and motivation. Asia-Pacific Forum on Science Learning and Teaching, v. 13, n. 1, p. 1-17, mar. 2012. Disponível em: https://www.eduhk.hk/apfslt/download/v13_issue1_files/gok.pdf. Acesso em: 13 out. 2019.

KAPUCU, Serkan; BAHÇIVAN, Eralp. High school students' scientific epistemological beliefs, self-efficacy in learning physics and attitudes toward physics: a structural equation model. Research in Science \& Technological Education, v. 33, n. 2, p. 252-267, mai. 2015. DOI: http:// dx.doi.org/10.1080/02635143.2015.1039976.

LIMA JUNIOR, Paulo Roberto Menezes. Evasão do ensino superior de Física segundo a tradição disposicionalista em sociologia da educação. Tese (Doutorado em Ensino de Física) - Instituto de Física, Universidade Federal do Rio Grande do Sul, Porto Alegre, 2013. Disponível em: https://lume.ufrgs.br/handle/10183/78438. Acesso em: 13 out. 2019.

LIMA JUNIOR, Paulo Roberto Menezes; OSTERMANN, Fernanda; REZENDE, Flavia. Análise dos condicionantes sociais da evasão e retenção em cursos de graduação em Física à luz da sociologia de Bourdieu. Revista Brasileira de Pesquisa em Educação em Ciências, v. 12, n. 1, p. 37-60, ago. 2012. Disponível em: https://periodicos.ufmg.br/index.php/rbpec/article/view/4218. Acesso em: 13 out. 2019.

MASSI, Luciana; VILLANI, Alberto. Um caso de contratendência: baixa evasão na licenciatura em química explicada pelas disposições e integrações. Educação e Pesquisa, v. 41, n. 4, p. 975-992, dez. 2015. DOI: http://dx.doi.org/10.1590/s1517-9702201512135667. 
MORAES, Kaluti Rossi De Martini; ESPINOSA, Tobias; HEIDEMANN, Leonardo Albuquerque. Métodos ativos de ensino podem ser entendidos como recursos para o combate à evasão em cursos de graduação em Física? Uma análise das relações entre os fundamentos de métodos ativos e a evasão universitária com base nas ideias de Vincent Tinto. Caderno Brasileiro de Ensino de Física, submetido.

MOREIRA, Marco Antonio. Avaliação da Aprendizagem. Disponível em: http://www.if.ufrgs. br/cref/uab/midias/apoio/avaliacao.pdf. Acesso em: 13 out. 2019.

OLIVEIRA, Vagner; ARAUJO, Ives Solano; VEIT, Eliane Angela. Resolução de problemas abertos no ensino de física: uma revisão da literatura. Revista Brasileira de Ensino Física, v. 39, n. 3, jan. 2017. DOI: http://dx.doi.org/10.1590/1806-9126-rbef-2016-0269.

PALHARINI, Francisco de Assis. Elementos para a compreensão do fenômeno da evasão na UFF. Avaliação: Revista da Avaliação da Educação Superior, v. 9, n. 2, p. 51-80, mar. 2004. Disponível em: http://periodicos.uniso.br/ojs/index.php/avaliacao/article/view/1268. Acesso em: 13 out. 2019.

SALDAÑA, Paulo. Folha de São Paulo. Quase 50\% dos professores não têm formação na matéria que ensinam. 2017. Disponível em: http://www1.folha.uol.com.br/educacao/2017/01/1852259-quase-50-dos-professores-nao-tem-formacao-na-materia-que-ensinam.shtml. Acesso em: 13 out. 2019.

SANTOS, Madge Bianchi dos; ARAUJO, Ives Solano; VEIT, Eliane Angela. Uma sequência didática sobre ondas com os métodos Instrução pelos Colegas (Peer Instruction) e Ensino sob Medida (Just-in-time Teaching). Textos de Apoio ao Professor de Física. Porto Alegre: UFRGS, 2016. Disponível em: http://www.if.ufrgs.br/public/tapf/tapf_v27n5_bianchi.pdf. Acesso em: 13 out. 2019.

SAWTELLE, Vashti; BREWE, Eric; GOERTZEN, Renee Michelle; KRAMER, Laird H. Identifying events that impact self-efficacy in physics learning. Physical Review Special Topics - Physics Education Research, v. 8, n. 2, p. 1-17, set. 2012. DOI: http://dx.doi.org/10.1103/ PhysRevSTPER.8.020111.

SILVA, Saulo Luis Lima da; FUMIÃ, Herman Fialho. É seguro atirar para cima? Uma analise da letalidade de projéteis subsônicos. Revista Brasileira de Ensino de Física, v. 41, n. 3, nov. 2018. DOI: http://dx.doi.org/10.1590/1806-9126-rbef-2018-0260.

SILVEIRA, Fernando Lang; PEDUZZI, Luis O. Q. Três episódios de descoberta científica: da caricatura empirista a uma outra história. Caderno Brasileiro de Ensino de Física, v. 23, n. 1, p. 26-52, mar. 2006. Disponível em: https://periodicos.ufsc.br/index.php/fisica/article/view/6289. Acesso em: 13 out. 2019.

TINTO, Vincent. Dropout from higher education: A theoretical synthesis of recent research. Review of Educational Research, v. 45, n. 1, p. 89-125., 1975. DOI: https://doi.org/10.3102/00346543045001089.

TINTO, Vincent. Leaving college: rethinking the causes and cures of student attrition. Chicago: University of Chicago Press, 1993.

TINTO, Vincent. Through the Eyes of Students. Journal of College Student Retention: Research, Theory \& Practice, v. 0, p. 1-16, dez. 2017. DOI: https://doi.org/10.1177/1521025115621917.

ZANIEWSKI, Anna M.; REINHOLZ, Daniel. Increasing STEM success: a near-peer mentoring program in the physical sciences. International Journal of STEM Education, v. 3, n. 14, mai. 2016. DOI: https://doi.org/10.1186/s40594-016-0043-2. 